\title{
KÜRESELLEŞEN DÜNYADA AHLAK TASAVVURU
}

\section{Özet}

Son çalışmalar ahlaki davranışın ahlak tasavvuru tarafından belirlendiğini ortaya koymaktadır. Bu çalışma ahlaki davranışların nasıl ahlak tasavvuru tarafından belirlendiğini açıkladıktan sonra küreselleşmenin ahlak tasavvuru üzerindeki etkilerini incelemektedir. İkinci olarak ahlak tasavvurunun küreselleşmesi ile yerelle bağlantısının sekteye uğraması araştırılmaktadır. Üçüncü ve dördüncü olarak, kültür endüstrisinin ve kültürel emperyalizmin ahlak tasavvurunda meydana getirdiği tek tipleştirme tartışılmaktadır. Daha sonra küreselleşmenin ahlak tasavvurunda meydana getirdiği parçalanma ele alınmaktadır. Son olarak küreselleşme, din ve ahlak tasavvuru konuları incelenmektedir.

Anahtar kelimeler: Ahlak tasavvuru, Küreselleşme, Kültür Endüstrisi, Kültürel Emperyalizm.

\section{Abstract}

\section{Moral Imagination in the Globalized World}

Contemporary works show that moral behaviors have been determined by moral imagination. This work surveys the effects of globalizations on moral imagination after explaining how moral behaviors have been determined by moral imagination. Second, it is investigated how globalization of moral imagination breaks the relationship between locality and moral imagination. Third and forth, it is discussed that culture industry and cultural imperialism induce standardization of moral imagination. Afterwards, it is examined that globalization brings about disruption in moral imagination. Finally, the topics of globalization, religion and moral imagination are studied.

Key words: Moral Imagination, Globalization, Culture Industry, Cultural Imperialism.

\section{Giriş}

Ahlaki davranışın ahlaki normlardan mı yoksa normları da kapsayan bir ahlak tasavvurundan mı kaynaklandığı sorusu günümüzde de sorulmaya devam ederken, bir de bu konuya küreselleşme tartışmaları eklendi. Biz de bu makalede ahlaki davranışın ahlak tasavvuru tarafından belirlendiği düşüncesiyle küreselleşen dünyanın ahlak tasavvuru üzerindeki etkilerini incelemeye çalışacağız. Böylece biz ne bir ahlak felsefesi yapmaya çalışacağız ne de küreselleşme-

* $\quad$ Doç. Dr., İstanbul Üniversitesi, İlahiyat Fakültesi 
nin ontolojik yapısı hakkındaki tartışmalara gireceğiz. Bizim yapmaya çalıştığımız ahlak tasavvurunun küreselleşen dünyada nasıl oluştuğuna dair ipuçlarını yakalamaya çalışmaktan ibaret olacak.

Küreselleşmenin ahlak tasavvuru üzerindeki etkilerini incelerken öncelikle ahlak tasavvurundan ne kastettiğimizi açıklayarak ahlak tasavvurunun ahlaki davranışı nasıl oluşturduğu üzerinde kısaca duracağız. Ahlak tasavvuru tartışmamız bizim küreselleşme tartışmalarımıza bir zemin hazırlayacak. Böylece küreselleşmenin ahlak tasavvuru üzerindeki etkilerini teorik ve pratik açıdan ortaya koyabileceğiz.

Dolayısıyla ilk olarak ahlak tasavvurunu tartışacağız. İkinci olarak ahlak tasavvurunun nasıl yerellikten çıkıp küreselleştiği üzerinde duracağız. Üçüncü olarak ahlak tasavvurunun oluşumunda etkili olan hikâye etme türlerini tekeline alan ve küreselleşmeyle tüm dünyaya yayılan kültür endüstrisini inceleyeceğiz. Dördüncü olarak, küreselleşme ile daha da etkinliğini artıran kültürel emperyalizm ile ahlak tasavvuru arasındaki ilişkiyi açıklayacağız. Daha sonra küreselleşen dünyada ahlak tasavvurunun nasıl bir parçalanmaya uğradığını tartışacağız. Son olarak küreselleşme, din ve ahlak tasavvuru konusunu ele alacağız.

\begin{abstract}
Ahlak Tasavvuru
Mark Johnson'un ifade ettiği gibi biz insanlar tasavvur yönü ağırlık basan varlıklarız; gündelik refleksi davranışlarımızdan tutun da en soyut düşünme tarzlarımız ve akıl yürütmelerimize kadar tasavvur yetimizin içinde rol almadığ davranış şekillerimiz yok gibidir. Bizlerin ahlak anlayışı büyük ölçüde tasavvur şemaları, mecazlar ve hikâyeler gibi tasavvur yapılarına dayanmaktadır. ${ }^{1}$

Benedict, M. Guevin Kathlen Fischer'in tasavvur çalışmasını özetleyerek bu konuda bize önemli bakış acıları sunmaktadır. Bu özete göre tasavvur hayatta üç önemli rolü oynamaktadır. İlk olarak, tasavvur bizim kendisiyle gerçeği anladığımız bir araçtır. İkinci olarak, tasavvurun ortaya çıkmasını sağlayan anlatıcı dil derin anlamların dilidir ve mantıksal ve ampirik verilerin dışındaki insan oğlunun tecrübesinden kaynaklanır. Bundan dolayı tasavvurun dili sembolik ve mecazidir. Üçüncü olarak tasavvur bizi başka dünyalara taşıyan bir
\end{abstract}

1 Mark Johnson, Moral Imagination, The University of Chicago Press, Chicago ve London. 1993, s.IX. 
araçtır. $^{2}$

Tasavvurun ahlak hayatımıza müdahalesi ise ahlak tasavvuru yoluyla gerçekleşir. Çünkü biz, ahlaki kişiliğimizi ve davranışlarımızı Johnson'un söylediği gibi ancak kendi hayat hikâyemiz kontekstinde anlayabiliriz. Kişilikle onun hareketlerinin bütünlüğü ancak kişinin kendi hikâyesinde yatar. Bu hikâye bütünlügü de kendisi sayesinde olayların akışına göre tutarlı davranışlar sergilediğimiz çeşitli tasavvur sentezlerinin bir sonucu olarak ortaya çıkar. ${ }^{3}$ Bu açıklama bize hikâye türleri diye nitelediğimiz hikâyeler, filimler ve diğer anlatı türlerinin bizim ahlak gelişimimizdeki ve bazı durumlarda nasıl davranmamız gerektiğini belirlemede ki önemli rolünü ortaya çıkarmaktadır. Çünkü William Barbieri'nin ifade ettiği gibi ahlaki tecrübemiz daha önceki hikâyeleri şekillendiren ve onlar tarafından şekillendirilen hikâye etme şekilleriyle oluşur. Bizim kişiliğimiz, karakterimiz bu hikâyelerden ortaya çıkar ve hareketlerimiz bir anlamda bu hikâyeler tarafından belirlenir. ${ }^{4}$

Eğer hikâye etme şekilleri ahlak tasavvurumuzu belirliyor ve dolaylı olarak hareketlerimizi şekillendiriyorsa küreselleşen dünyanın hikâye etme şekilleri ve tarzları üzerindeki etkileri incelenmeye değer bir konu olarak öne çımaktadır. Tam da biz bu makalede bu konu üzerinde durmak bu sorulara cevap niteliğindeki ipuçlarını yakalamak niyetindeyiz. İlk olarak hikâye etme türlerinin nasıl olup da yerellikten bağlarını kopararak küreselliğe ulaştığını anlamaya çalışacağız.

\section{Küreselleşen Hikâye Etme Türleri}

Küreselleşen hikâye etme türlerinden kastımız, yerel olmayan güçlerin bir şekilde hikâye etme türlerinde rol oynamaya başlamaları olarak tarif edebiliriz. Böylece hikâye etme türlerinde sınırlar kalkmış ve uzak yerlerden esintiler hissedilmeye başlanmıştır. Sınırların kalkması aynı zamanda hikâye etme türlerindeki tutarlılığ $\mathrm{da}$ tehdit eder hale gelmiştir.

Ahlak tasavvuru denildiği zaman genellikle yerel ve ahenkli olacağı düşünülmekteydi. Fakat küreselleşme ahlak tasavvuru ile yerellik arasındaki bağlantıyı kopartmıştır. Yerel ahlak tasavvuruna uzaktan müdahaleler olmaya

2 Benedict M Guevin, "The Moral Imagination and the Shaping Power of the Parables", The Journal of Religious Ethics, 1989, say1: 17, s.64.

3 Johnson, age, s. 164.

4 William Barbieri, "Ethics and the Narrated Life", Journal of Religion, 1998, say1:78, s. 369. 
başlamıştır.

Mesela küreselleşme öncesi hikâyeler belli bir dinin veya yerin motiflerini taşırken ve o mekânda yerleşik bulunan kimselerin çoğu tarafından paylaşılırken, küreselleşmeyle birlikte Türkiye' deki herhangi bir birey de Spellberge'in romanlarını okur, onun romanlarından senaryosu yazılan filmleri seyreder hale gelmiştir. Böylece Türkiye'deki bireylerin tasavvurları ve ahlak tasavvurları Amerika'da yazılan ve çizilen hikâye etme türleri tarafından belirlenir hale gelmiştir. Bu olaylar ahlak tasavvurunun oluşumunda artık sınırların önemsizliğini ortaya koymaktadır.

Küreselleşme öncesi yerel hikâyeler bireye hegemonik bir şekilde belli bir ahlak tasavvuru vererek onu hayatin kaosuna karşı korurken küreselleşme bu hegemonyayı kırmış ve bireyi yeni hikâyelerle tanıştırmıştır. Böylece yerel hikâyeler tartışılmaz konumlarından inmek zorunda kalmışlar ve bireyin tasavvurunu belirlemedeki eski güçlerini kaybetmişlerdir. Bireye daha fazla seçenek sunduğu için küreselleşme bireye daha fazla özgürlük veriyor olmasına rağmen, bu seçeneklerin de belli gruplar tarafından belirlenmesi modern bir despotluğun ortaya çıkmasını sağlamıştır. Bu despotluğun arkasında iki temel sebep bulunmaktadır: 1) Kültür Endüstrisi ve 2) Kültürel Emperyalizm.

\section{Kültür Endüstrisi}

Theodor Adorno ve meslektaşı Max Horkheimer'in kullandığı kültür endüstrisi kavramı kapitalist sistemin kar amaçlı olarak ürettiği eğlence endüstrisi ve bu endüstrinin film ve müzik gibi seri üretimlerini işaret etmektedir. Bu iki araştırmacıya göre, kar amaçlı olarak üretilen bu seri ürünler faydasız ve aptalca şeyleri içerebilmektedir. Tüketici bu seri ürünleri kabule zorlanmaktadır. Adorno'ya göre, kültür endüstrisinin pratiği kar amacını kültürel formlara dönüştürebilme yetisidir. Bu kültürel formlar, yaratıcıları için kar getiren metalar halinde piyasaya çıktıkları andan itibaren kar amaçlı olarak var olmuşlardir. ${ }^{5}$

Bu kültürel ürünler bireylerin tasavvurunu sınırlar ve siyasal ve kültürel olarak pasif kalmalarını sağlarlar. Bu ürünler aracilığıyla insanların tasavvurları standartlaştırılır. Kültür endüstrisinin en önemli özelliklerinden birisi kültürel ürünleri ve dolayısıyla bu ürünleri tüketenleri standartlaştırmasıdır. Ador-

5 Theodor W Adorno (edit.), The Culture Industry: Selected Essays on Mass Culture, Routledge, London ve New York 1991, s. 99. 
no'ya göre, endüstri kavramı tamamen literal anlamda kastedilmemektedir. Bu kavram sadece üretim sürecine değil, daha çok standardizasyona işaret etmektedir. ${ }^{6}$ Tüm tüketicilere hitap edebilmek için ürünler arasında basit ve küçük farklılıklar oluşturulmaktadır. Sadece stil veya ayrıntıya dönük farklılıklarla tüm insanlara hitap edilmeye çalışılmaktadır. Böylece insanların kültürel zevkleri daha da önemlisi tasavvur yetileri standartlaştırılmaktadır. Ahlaki tasavvurları da bu standartlaşmadan teğet geçememektedir. Böylece standart bir ahlak tasavvuru bu kültürel ürünleri tüketenler arasında yayılmaktadır.

Kapitalizmin küreselleşmesi ile kültür endüstrisi de iki anlamda küreselleşmiştir. İlk olarak kapitalizmin temel yapılarının bulunduğu Batı ülkelerinde üretilen kültürel ürünlerin diğer ülkelere ihraç edilmesi ki bunu kültür emperyalizmi başlığı altında inceleyeceğiz. İkinci olarak, her ülkeye ait kültür endüstrileri ortaya çıkmıştır. Amacı kar elde etmek olan ve bu amaç uğruna seri kültürel ürünler üreten her ülkenin kültür endüstrisi o ülkenin yerel kültürünü temsil etmeye çalışsa bile ulusal boyutta standart ürünler, zevkler ve tasavvurlar üretmektedir. Milyonlarca insanı televizyon başına çeken şiddet ve aşırı müstehcenlik içeren pembe dizilerin yayınlanmasındaki temel nokta kar amacıdır. Bu gibi dizilerin insanların ahlak tasavvuru oluşumlarındaki negatif etkileri reyting uğruna görmezlikten gelinmektedir. Buradaki küreselleşmenin etkisi kapitalist mantığın ve alışkanlıkların küreselleşmesidir. Bu alışkanlıklar ve mantık çerçevesinde yerel motifleri içeren kültürel ürünlerin imal edilmesi ve sunulması kapitalizmin küreselleşmesinin bir sonucudur.

Yerel kültürde anlamı olan ve insanların hayatına anlam katan birçok unsur kültür endüstrisi için de konu olabilmektedir. Fakat kültür endüstrisi bu motifleri kaynağından soyutlayarak, içini boşaltarak insanlara tüketmeleri için sunmaktadır. Bir önceki nesil için çok anlam ifade eden birçok yerel motif yeni nesiller için sadece tüketilecek bir meta haline gelmektedir. Bu durum genç nesillerin ahlak tasavvurlarına da etki etmektedir.

\section{Kültürel Emperyalizm}

Kültürel emperyalizm kültüre dayalı daha dolaylı bir egemenlik anlamını ima etmektedir. Batı ülkelerinin sömürgeleştirdikleri ülkeler üzerindeki doğrudan ekonomik, politik ve sosyal egemenlikleri, medyanın ve kültür endüstrisinin toplumsal hayata yön verdiği postmodern dünyada kültürel egemenliğe dö-

6 Adorno, age, s. 100. 
nüşmüştür. Bu sosyal, siyasi ve kültürel duruma genel bir ifade ile kültürel emperyalizm ismini vermekteyiz. John Tomlinson'un ifade ettiği gibi kültürel emperyalizmin birçok boyutu bulunmaktadır. ${ }^{7}$ Fakat biz burada daha çok medya ve ekonomik boyutunu ele almaktayı.

Kültürel emperyalizm ile egemen ülkeler kendi yaşam şekillerini, tercihlerini ve tüketim alışkanlıklarını diğer ülkelere medya aracılı̆̆ıyla dayatmaktadır. Böylece kendi şirketleri ürettikleri malları bu ülkelere satabilmekte ve söz konusu ülkelerin zenginlikleri ve tasarrufları sömürülebilmektedir.

Kültürel emperyalizm özellikle Amerikan hayat tarzı, tüketim alışkanlıkları ve kültürel ürünlerinin diğer ülkelerde yaygınlık kazanmasını sağlamaktadır. Özellikle tüketim kültürü Amerika ve Batı kodlarıyla diğer ülkelerde yaygınlaşmaya başlamaktadır. Susamaktan daha fazla kolasayan bir gençliğin ortaya çıkması kültürel emperyalizmin etkilerini gösteren güzel bir örnektir. Mcdonald'sda hamburgerini yiyen, starbucks kafelerde kahvesini içen, Madonna dinleyen Amerikan filmleri izleyen, kot pantolon giyen yeni nesil ile ebeveynleri arasındaki yaşam tarzı farkını açıklayan en önemli unsur küreselleşen dünyadaki kültürel emperyalizmdir.

Kültürel emperyalizmin de katkılarıyla tüketim kültürünün Amerikan ve Batı kodlarıyla yayılması, hiç kuşkusuz Batı dışında yaşayan insanların ahlak tasavvurları üzerinde etkileri olmuştur. Amerikan rüyası birçok insanın tasavvurunda önemli bir yer tutmaya başlamıştır. Kendini merkeze alan, hazcı ve bencil bir hayat tarzını beraberinde getiren tüketim kültürü Batı dışı toplumların ahlak tasavvurlarında travmalara yol açmaktadır. Kuşaklar arası farkları bir tarafa bırakın, bireyler en azından iki farklı sosyalleşme ve dolayısıyla iki farklı ahlak tasavvuruyla karşı karşıya kalmaktadırlar.

Bir tarafta erdeme, sabra, empatiye, sosyal dayanışmaya ve rahmete vurgu yapan İslam kültürü ve bu konuları işleyen yerel hikâyeler, diğer tarafta ise bireyin hazzını ve isteklerini merkeze alan, anı yaşama sloganını sunan tüketim kültürü ve bu kültürün empoze edildiği filmler, videolar, klipler, çizgi filmler, reklamlar ve daha birçok Batı endeksli kültür endüstrisi ürünü. Bu iki farklı ahlak tasavvuruna maruz kalan bireyin tutarlı bir sentez oluşturması kolay olmaz. Birçok kişi farkında olmadan içselleştirdiği bu iki farklı ahlak tasavvuru sonucu, tutarsız ahlaki davranışlar sergileyebilmektedir. Emile Durkheim'in tabiri ile ahlak tasavvurunda ve dolayısıyla ahlaki davranışlarda bir anomik

7 bk. John Tomlinson, Cultural Imperialism, Continuum, London 1991. 
(kargaşa) durum meydana gelmektedir. ${ }^{8}$

Durkheim anomi tabirini geçiş dönemlerinde ortaya çıkan normsuzluk olarak tarif etmektedir. Anomik durumun sapkınlıkları ve suçu artırdığına dair birçok çalışma bulunmaktadır. Ahlak tasavvurundaki anomik durumun ahlaki davranışlarda farklılıklar ortaya çıkarması doğaldır. Bu anomik durumu daha da derinleştiren ahlak tasavvurunun küreselleşme ile parçalanmasıdır.

\section{Parçalanan Ahlak Tasavvuru}

Bu bölümde Arjun Appadurai'nin parçalanma teorisini ele alıp, ahlak tasavvuruna uygulayacağız. Appadurai'ye göre, tasavvurdaki parçalanmanın en önemli iki sebebi medya ve göçtür. Medya ve göç özellikle ulus-devlet tanımındaki tirenin anlamsızlaşmasını sağlamaktadır. ${ }^{9}$ Medya ve göç kültürel ekonomide parçalanmalara sebebiyet verdikleri için ulus-devlet kavramı toplumsal hayatta önemini kaybetmektedir. ${ }^{10}$

Appadurai'ye göre, küresel kültürel ekonomideki parçalanma, ekonomi, kültür ve politikanın birbirlerinden kopmasından kaynaklanmaktadır. Bu kopma beş farklı boyutta kendini göstermektedir: (1) etnik alan, (2) medya ala$\mathrm{n}$, (3) teknik alan, (4) finans alanı ve (5) fikir alanı. ${ }^{11}$

Etnik alandan kastı, dünyanın değişimine katkıda bulunan turist, mülteci, göçmen misafir işçiler gibi kendi ülkelerinden başka ülkelere çeşitli sebeplerden dolayı giden insanlardır. ${ }^{12} \mathrm{Bu}$ insanların hem kendi ahlak tasavvurlarında önemli kırılmalar olmakta hem de gittikleri ülkelerin insanlarına farklı bir ahlak tasavvuru sunmaktadırlar.

Teknolojik alandan kastı, teknolojinin ülkeler arasında çok hızlı bir şekilde yayılması ve sınırların anlamsız hale gelmesidir. Birçok şirketin fabrikası farklı bir ülkede bulunmakta, üretilen malların dağıtımı farklı bir ülkeden gerçekleştirilmektedir. Bunun sebebi ülkeler arasındaki akışkanlıklar, işçi gücü gibi çeşitli etkenlerden kaynaklanmaktadır. ${ }^{13}$ Teknolojinin ülkeler arasında bu kadar

8 Bk. Emile Durkheim, Division of Labor in Society, Macmillan Press, London 1984.

9 Arjun Appadurai, Modernity at Large: Cultural Dimensions of Globalization, University of Minnesota Pres,: Minnesota 1996, s. 3.

10 Appadurai, age, s. 19.

11 Appadurai, age, s. 33.

12 Appadurai, age, s. 33.

13 Appadurai, age, s. 34. 
hızlı yayılması bireylerin ahlak tasavvurlarını da etkilemektedir. İnternetin ve cep telefonlarının çok hızlı yaygınlaşması bireylerin tasavvurlarının bulundukları ülke ile sınırlı kalmasını önlemektedir. Daha geniş ve daha farklı ahlak tasavvurlarına maruz kalma ihtimallerini artırmaktadır.

İletişim teknolojilerinin gelişmesi ile birlikte özellikle televizyon ve internetin yaygınlaşmasıyla kültür bizzat bir materyal gerçekliğin sembollerle ifadesi olmasının ötesine geçmiş, bu iletişim araçlarındaki sembollerin sembolü olma durumuna gelmiştir. Sanal ilişkiler ikili ilişkilerin yerini almaya başlamış, sanal görüntüler gerçek manzaralardan daha bir gerçek hale gelmiş, sanal olaylar gerçek olaylardan bazı durumlarda daha da önemli olmuşlardır. Bütün bu gelişmeler ahlak tasavvuru üzerinde önemli etkiler göstermektedir.

Sanal komşuluklar oluşacak, sanal gündem konuları meydana gelecek ve insanların tasavvurlarında sanal âlem önemli bir yer tutacak. Böylece yerellikle ve gerçek hayatla bağlantısında önemli kesiklikler oluşacak. Doğal olarak bu durum kişinin ahlak tasavvuruna dolayısıyla davranışlarına yansıyacaktır.

Finans alanı ise para hareketlerini ifade etmektedir. Para hareketleri, sıcak para veya doğrudan yatırım olabilir. Her iki durumda da ulus devletlerinin sınırları küreselleşmeyle birlikte önemsizleşmektedir.

Appadurai medya alanı olarak da medya tarafından oluşturulan imajların, üretilen haberlerin ve propagandanın dünyaya yayılmasını kastetmektedir. ${ }^{14}$ Kültürel emperyalizm bölümünde bu konulara değindiğimiz için şimdi tekrar bu konulara girmeyeceğiz.

Son olarak fikirler alanı olarak çeşitli fikirlerin, yaklaşımların ve ekollerin dünya çapında çok hızlı yayılması ve ulusal sınırların bu yayılmayı engelleyememesi. Devletlerin propagandaları, sosyal hareketlerin karşı propagandaları ve değişik ideolojiler fikirler alanını oluşturmaktadır.

Appadurai'nin parçalanma teorisi kültürel, politik ve ekonomik alanın birbirinden ayrılması anlamına gelmektedir. Appadurai'ye göre, küreselleşme sadece yerelliğin kaybolması anlamına gelmeyip aynı zamanda söz konusu bu üç alanın bir birinden kopması anlamına da gelmektedir. Ahlak tasavvuruna bu durumun etkisi ahlak tasavvurunda da bir parçalanmanın oluşmasıdır.

Eskiden politik, ekonomik ve kültürel alan bütün olduğu için bireylerin ahlak tasavvurlarında da bir ahenk bulunmakta idi. Fakat küreselleşme ile bu üç alan farklılaştı̆̆ için politik tasavvur ile kültürel tasavvur bazen birbirlerini

14 Appadurai, age, s.35. 
nakzedecek derecede farklılaşmaktadır. Hem politik, hem ekonomik hem de kültürel tasavvuru kapsayan ahlak tasavvuru da doğal olarak parçalanmaktadır. Politik olarak doğru kabul edilen bir davranış bazen kültürel olarak, bazen de ekonomik olarak doğru olmaması bu parçalanmaya örnektir.

Bu parçalanmışlık bir taraftan kişilere seçme hakkı vererek ahlak tasavvurunu genişletmesine rağmen diğer taraftan bireylerin tutarlı davranışlar sergilemelerini zorlaştırmaktadır. Bu süreçle birlikte, yerelle bağlantısı kalmamış etnik, medyatik, fikri ve teknolojik alanlar kendilerine özgü hale gelmektedir.

\section{Küreselleşme, Din ve Ahlak Tasavvuru}

Küreselleşme hem açık büfe dini hareketleri hem de radikal dini hareketleri beslemektedir. Küreselleşme ile birlikte birçok din diğer dinlerle bir arada yaşamak ve bulunmak zorunda kalmıştır. Bir arada yaşama dinlerin önceki hegemonik durumlarının kaybolmasına sebep olmuş ve dinler açık büfedeki yemekler gibi birer seçenek haline gelmişlerdir. Kapitalist kültürün de etkisiyle kendini merkeze alan bireyler istedikleri dinlerden istedikleri değerleri, ritüelleri ve inançları alıp ona göre bir yaşam tarzı kurmaya başlamışlardır. Açık büfe din ahlak tasavvurunda dolayısıyla ahlaki tutum ve davranışlarda etkisini göstermektedir. Melez ahlak tasavvurları açık büfe dinin bir sonucu olarak ortaya çıkmaktadır.

Kesinliğin olmadığı, birçok ahlaki tutumun bulunduğu ortama bir tepki olarak göreceliği tamamen reddeden radikal dini hareketler de aslında küreselleşmenin bir ürünüdür. Radikal dini hareketler ulus devlet sınırlarını aşmakta ve küresel bir düzey kazanmaktadırlar. Bu hareketler dünyaya ve dine bakışlarını mutlaklaştırdıkları için kendi içinde daha tutarlı ahlak tasavvurları vaat etmektedir. Bu vaat de bazı kişilere cazip gelmektedir.

\section{Sonuç}

Bu makalede ilk olarak ahlaki tasavvurun ahlaki davranışın oluşumundaki katkılarını anlamaya çalıştık. Modern zamanlarda Kartezyen felsefesinin bir sonucu olarak ahlaki davranışının ahlak kuralları ile belirlendiği düşüncesi hâkimdi. Son dönem düşünürler ise ahlaki davranışların bireylerin ahlak tasavvuruyla birebir bağlantılı olduğunu ortaya koymuşlardır. Biz de son dönem yazarların düşüncelerini aktararak ahlaki davranışların ahlak tasavvuru tarafından belirlendiği düşüncesini vurguladık.

İkinci bölümde, küreselleşme ile ahlak tasavvurunun yerellikle olan bağla- 
rının nasıl zayıfladığı üzerinde durduk. Küreselleşme ulusal sınırların etkinliğini aşındırmış ve insanları uzak diyarların esintileriyle baş başa bırakmıştır. Ahlak tasavvuru da küreselleşme öncesinde yerel hikâyelerin kodlarıyla bezenirken küreselleşme ile birlikte farklı ülkelerin hikâyeleri ve kodları devreye girmiş, yerel hikâyelerin ahlak tasavvuru üzerindeki hegemonyasını aşındırarak alternatif hikâyeler sunmuşlardır. Çeşitli ahlak tasavvurları bireylere seçenekler sağlayarak özgürlük alanlarını genişletiyor olsa da kültür endüstri ve kültürel emperyalizm küresel düzeyde yeni bir tek tipleşmeyi beraberinde getirmektedir.

Üçüncü ve dördüncü bölümde dünya çapında tek tip hayat tarzını dayatan kültür endüstrisini ve kültürel emperyalizmi inceledik. Kültür endüstrisi kültürel ürünlere kar amaçlı yaklaşarak bu ürünleri standartlaştırırken, kültür emperyalizmi ise Batı ülkelerine ait şirketlerin daha çok mal satmasını sağlayarak dolaylı sömürüyü devam ettirebilmek için Batı hayat tarzını diğer toplumlara empoze etmektedir. Dolayısıyla tüketim kültürü yeni nesilde yepyeni bir tasavvur ve dolayısıyla ahlak tasavvuru oluşturmaktadır. Tüketim kültürünün kodlarıyla oluşan bu yeni tasavvur yerel ahlak tasavvuru ile bazen karşı karş1ya gelmektedir. Bu da doğal olarak tutarsız ahlak tasavvurlarının ve davranışların oluşumuna sebep olmaktadır. Bu duruma bir de beşinci bölümde tartıştığımız ahlak tasavvurunun parçalanması eklenmektedir.

Son bölümde ise küreselleşme ekseninde din ve ahlak tasavvuru ilişkisini tartıştık. Küreselleşme ile birlikte dinler eski hegemonik güçlerini kaybetmişler ve açık büfe din tabiri ortaya çıkmıştır. Açık büfe dinde dinler açık büfedeki yemekler gibi seçenek haline gelmekte ve bireyler kendi arzu ve isteklerine göre dinlerden istediklerini almaktadırlar. Dolayısıyla dinler tarafından ileri sürülen çeşitli ahlak tasavvurları da piyasada yer almakta ve bireylerin tercihine sunulmaktadır.

Genel bir değerlendirme olarak küreselleşme ahlaki tasavvurun yerel bağlamını zayıflatmıştır. Ayrıca tek tip ahlak tasavvuru kültür endüstrisi ve kültürel emperyalizm tarafından bireylere dayatılmaktadır. Bu durum şu anda geçici anomik durum oluşturmaktadır. Bu anomik duruma bir cevap olarak evrensellik iddiası olan dinler tekrar ahlak tasavvurunda yetkin konumlarına ulaşma emareleri göstermektedirler. 


\section{Kaynakça}

Adorno, Theodor W. der., The Culture Industry: Selected Essays on Mass Culture, Routledge, London ve New York 1991.

Appadurai, Arjun, Modernity at Large: Cultural Dimensions of Globalization,

University of Minnesota Press, Minnesota 1996.

Barbieri, William, "Ethics and the Narrated Life", Journal of Religion, 1998, say1: 78, ss. 361-386.

Durkheim, Emile, Division of Labor in Society, Macmillan Press, London 1984.

Guevin, Benedict M, "The Moral Imagination and the Shaping Power of the Parables", The Journal of Religious Ethics 1989, sayı: 17, ss. 63-79.

Johnson, Mark, Moral Imagination, The University of Chicago Press, Chicago ve London 1993.

Tomlinson, John, Cultural Imperialism, Continuum, London 1991. 